\title{
ARTICULATING EXPECTATIONS ABOUT SUPERVISION
}

\section{GETTING IT RIGHT AT THE START OF THE JOURNEY}

Lorna Moxham, Ellie Taylor, Trudy Dwyer, William

Lauder, Moira Stephens, Carolyn Antoniou, Michelle Roxburgh, Kerry Reid-Searl, Angela E.

Chan \& Catherine Fuller

\section{INTRODUCTION}

Studying for a research higher degree (RHD) provides enormous prestige for the candidate as this is considered one of the highest academic qualifications achievable. Within the RHD hierarchy, the Doctor of Philosophy $(\mathrm{PhD})$ is often promoted as the pinnacle. $\mathrm{A} \mathrm{PhD}$ is an advanced academic qualification frequently viewed as the number one mandatory qualification for the majority of academic and research positions across a wide range of disciplines. $\mathrm{PhDs}$ do, by their very nature, provide a significant contribution to new knowledge and understanding within the context of a particular discipline area.

In terms of esteem, the reputation of the RHD supervisor or supervisory panel is enhanced if the supervisor can 'claim' that his/her student's completion is 'on time' and has not returned requiring major revisions. Successful, timely completions are not always the norm though, and the RHD journey, which is a marathon and not a sprint, can be challenging. Numerous factors influence successful and on-time completion. Submission within the allocated timing bracket, which is becoming increasingly tighter as the compliance approach to quality more and more takes hold, is of mounting importance to universities. This is because RHD funding by governments is often tied to the timeliness of finishing. Despite objections by many members of the academy who feel this type of approach does not account for heterogeneity, many universities respond to fiscal pressures and compliance by levying fees on 'over-time' students. Given such pressures, a much greater interest is 
now given to research supervision. Reaching the stage of thesis submission is hard, with candidate withdrawal thought to be dishearteningly high (Mittwede, Noch \& Guo 2014:958-959; Litalien \& Guay 2015:218-231).

Most scholars accept that many RHD roads can be bumpy, so what can be done to help 'smooth' the road and enhance successful and timely completion? This chapter suggests that one strategy to facilitate successful timely completion is to articulate expectations about supervision clearly at the start of the journey. This approach is of particular importance given that it is now well known that the relationship that the RHD candidate has with his/her supervisor is one of the most significant influences in terms of success (Yarwood-Ross \& Haigh 2014:38-43).

Supervision styles are disparate. Some supervisors consider their role to be designer and manager of the research study and to offer full pastoral support to the student. Others believe in minimal intervention, requiring students to manage themselves completely with very little pastoral support. Taylor and Kiley (2015:180-192) offer these concepts as two dimensions that have been dichotomised into low and high to generate four paradigms of supervisory style.

The laissez-faire style assumes that students are capable of managing both their study and self. Pastoral styles conceive that students can manage the study but need personal support. The directorial assumes that the student requires support in managing the study but not themselves, while the contractual style assumes the need for both personal and project support (Taylor \& Kiley 2015:180-192). The 'right' style depends on the supervisor-student 'fit'.

But that is just the point. How does a supervisor know which style to adopt and with which student? Given that no two projects are alike, and that RHD students and supervisors are clearly not a homogenous group, it is important to work out the most appropriate style, and this should be done at the 'get go'. Supervisors have to adapt, and if they cannot modify their style to ensure a good fit, perhaps a better match needs to be sought from elsewhere. Supervisors need to engage in self-reflection and understand what supervisory style they bring to the table.

\section{AIMING AT THE SAME TARGET}

The aim, of course, is to produce a quality thesis which is the embodiment of the results of the original research that took place. Guided by the supervisor(s), the candidate uses the thesis to demonstrate independent research skills and knowledge. Such abilities include the capacity to formulate a significant problem, to develop mastery of appropriate conceptual and methodological skills to investigate the problem, and 
to relate the research topic to a broader framework of knowledge. These abilities, as well as the commitment and discipline required when undertaking a doctoral programme, are the foundations upon which future generations of researchers grow. A positive RHD programme empowers neophyte researchers with nurturing environments that are stimulating and inspiring.

A significant enabler of - and sometimes, major obstacle to - timely completion, is the supervisory relationship. Traditional supervisor-centric relationships are increasingly being challenged. Universities are being urged to embrace contemporary research educational approaches instead of perpetuating what could be described as a transmissive approach to learning (Picard, Wilkinson \& Wirthensohn 2010:2133). There has been a conceptual shift in understanding and appreciating research education. A major contributor to re-examining the doctoral process came from the Carnegie Initiative on the Doctorate and the Association for the Study of Higher Education (ASHE) report (Gardener 2009:77-89). This report made sense of the networks, relationships and supports necessary in the formation of scholars, and has contributed to a position that embraces supervision as a shared responsibility and away from the apprentice-master model that maintained a power differential (Benmore 2014:1-14; Minichiello \& Kottler 2010:125-140). Given that both the quality and the quantity of supervision are shown to have a significant impact on the doctoral experience (Pyhältö, Vekkaila \& Keskinen 2015:4-16), supervisors are now encouraged to take an active role in the teaching and pedagogy of research (McCallin \& Nayar 2011:1-12). The supervisor who is responsive to student needs views a doctoral programme as a human educational relationship, one which is close and mutually respectful inclusive of the inevitable ups and downs (Connell \& Manathunga 2012:5).

Time, vigour and commitment are necessary from candidates and supervisors, if successful on-time completion is to be achieved. Despite a plethora of scholarly literature affirming the critical role that supervision contributes to the RHD journey (Lahenius \& Ikävalko 201 4:427-446; Moxham, Dwyer \& Reid-Searl 2013:345-354), many students describe supervision or lack thereof as the major barrier to successful and timely completion. Given the heterogeneity of RHD candidates (Dobson 2012), their needs in terms of supervision are not homogenous. Expectations vary widely amongst individuals and needs are not static during candidature. Supervisors and students often begin their relationship not knowing much at all about the other, so the question which is increasingly being asked, is how best to meet the needs of this dynamic and disparate cohort. Given then, that we do not know what we do not know about each other, understanding and appreciating subjective expectations 
as candidates begin their journey could be a positive strategy to commence on the right foot. This chapter contributes to this narrative by reporting on outcomes of an international research consortium that explored current RHD candidate and supervisor expectations of higher degree supervision.

According to Wilks (2006:15-22), students' expectations of their supervisors are not resolute at the commencement of candidature. Initial hopes and fears are often replaced by quite different concerns once students actually begin working with their supervisor. Problems that often arise only after the journey has begun could be minimised or prevented if an early intervention strategy regarding expectations is enacted. Nobody wants a bumpy, difficult journey and it is in everyone's best interest to avoid hazards where possible. If candidates and supervisors set out on the journey with clear expectations of their respective roles and understand not only the 'rules' related to their relationship, but also ways of communicating and interacting from the start, perhaps the 'bumps' can be avoided or at least minimised.

The early stages of candidature are when students negotiate, explicitly or implicitly, the boundaries of the supervisory relationship (Wilks 2006:15-22). But during these early stages the 'power' rests with the supervisor, and students are often reluctant to assert their opinions and expectations. Given this power imbalance, which remains very real at many institutions, processes need to be developed at the level of the academy that enable critical conversations to be had. Beginning a conversation with a powerful authority figure (supervisor) can be facilitated by establishing mandatory processes. This way, 'difficult' conversations about ways of working can be enacted as part of administrative processes and are not an affront to an individual. Such an approach can facilitate collegial relationships at the commencement of the research project rather than having students feeling disempowered and supervisors feeling confronted.

Kandlbinder and Peseta (2001:2-57) highlight three key elements of successful research supervision that facilitate the establishment of a cooperative and colearning relationship: establishing clear goals, developing partnerships, and managing the research process. Given the variety of supervisory styles the way in which supervisors respond to candidate expectations will be strongly influenced by their own philosophy of supervision.

The consensus in educational literature is that a positive relationship with an RHD supervisor is the key to successful and timely completion (Lange \& Baillie 2008:3034). It is therefore important to establish philosophical supervisory practice in terms of expectations. Identification of belief and style will assist both parties in developing an effective working relationship based on clear expectations from the beginning. 
Such an understanding could assist in both the selection of a supervisor and a student on the basis of 'philosophical best fit' that will facilitate collegiate working relationships.

\section{METHODS}

The study discussed in this chapter extended upon a smaller study conducted in Australia by Moxham et al (2013:345-354). A similar survey design was utilised, however a larger sample size was sought by extending invitations to universities across Australia, the UK, Hong Kong, and the USA. A purposive sample of RHD supervisors and candidates across the aforementioned locations were invited to participate. Ethical clearance was received from applicable Human Research Ethics Committees. Potential participants received an email with a link to an on-line, electronic version of the questionnaire (via Survey Monkey) and information which included an outline of the research and issues of consent. Participation was voluntary, and informed consent was gained via the questionnaire link by selecting 'Yes, I agree to participate in this research.'

The questionnaire contained demographic items and a series of closed-ended questions to elicit participants' expectations regarding RHD supervision. Expectations were measured using a five-point Likert scale format, with $1=$ The supervisor's responsibility alone; 2 = Mainly the supervisor's responsibility; $3=1 t$ is a joint and equal responsibility; $4=$ Mostly the student's responsibility; and $5=$ The student's responsibility alone. Altogether 996 people chose to participate; 389 were supervisors and 607 were RHD candidates.

\section{Data analysis}

Data were analysed using SPSS for Windows version 21 (SPSS Inc). Frequencies were calculated to gain a picture of demographic characteristics. Nominal data (dichotomous variables) were analysed using the Chi-square test. Comparisons between supervisors and candidates were determined through Mann Whitney $U$ analyses. A statistical significance level of $p<.05$ was set.

\section{RESULTS}

The majority of supervisors $(n=389)$ were female $(55 \%)$, had held their own PhD for more than 10 years (62.2\%), and were the supervisor or co-supervisor for between one and six students. The majority of RHD candidates $(n=607)$ were female $(68 \%)$. Only $65 \%$ of candidates had attended an RHD orientation session, and $20.8 \%$ of 


\section{PART THREE • CHANGING EXPECTATIONS OF POSTGRADUATE STUDENTS AND SUPERVISORS}

candidates had changed their supervisor since commencing their study. A variety of reasons were given for these changes.

Of the supervisors who completed the survey, 74.6\% were from Australia, $7.5 \%$ from the UK, 3.6\% from Hong Kong, and 14.4\% from the USA, and $72.6 \%$ of the RHD students were from Australia, 10.5\% from the UK, 5.8\% from Hong Kong, and $11.1 \%$ from the USA.

Candidate and supervisor age distributions are outlined in Table 8.1. Discipline areas for candidates are outlined in Table 8.2.

TABLE 8.1 Participant demographics

\begin{tabular}{|c|c|c|c|}
\hline & Age group & $\begin{array}{l}\text { Candidate frequency } \\
(n ; \%)\end{array}$ & $\begin{array}{l}\text { Supervisor frequency } \\
(n ; \%)\end{array}$ \\
\hline \multirow[t]{7}{*}{ Male } & 18 to 24 & $20 ; 10.3$ & 0 \\
\hline & 25 to 34 & $103 ; 53.1$ & $16 ; 9.2$ \\
\hline & 35 to 44 & $33 ; 17.0$ & $48 ; 27.6$ \\
\hline & 45 to 54 & $23 ; 11.9$ & $45 ; 25.9$ \\
\hline & 55 to 64 & $12 ; 6.2$ & $47 ; 27.0$ \\
\hline & 65 to 74 & $2 ; 1.0$ & $18 ; 10.3$ \\
\hline & $75+$ & $1 ; 0.5$ & 0 \\
\hline \multirow[t]{7}{*}{ Female } & 18 to 24 & $35 ; 8.5$ & 0 \\
\hline & 25 to 34 & $174 ; 42.4$ & $19 ; 8.8$ \\
\hline & 35 to 44 & $84 ; 20.5$ & $61 ; 28.4$ \\
\hline & 45 to 54 & $81 ; 19.8$ & $83 ; 38.6$ \\
\hline & 55 to 64 & $34 ; 8.3$ & $47 ; 21.9$ \\
\hline & 65 to 74 & $2 ; 0.5$ & $5 ; 2.3$ \\
\hline & $75+$ & 0 & 0 \\
\hline
\end{tabular}

TABLE 8.2 Candidates' discipline areas

\begin{tabular}{|l|l|l|l|l|l|l|l|l|}
\hline & Sci & Health & Nurs & Med & Educ & Engin/IT & Bus & $\begin{array}{l}\text { Law/Hum/ } \\
\text { Arts }\end{array}$ \\
\hline $\begin{array}{l}\text { Frequency } \\
\text { (\%) }\end{array}$ & 37.1 & 14.1 & 13.0 & 4.8 & 13.6 & 3.0 & 5.8 & 8.6 \\
\hline
\end{tabular}

Note. Sci $=$ Science; Nurs = Nursing; Med = Medicine $;$ Educ = Education \& Social Sciences;

Engin $=$ Engineering $;$ Bus $=$ Business $;$ Hum $=$ Humanities

The participants' responses to individual statements are presented in Table 8.3. 


\section{CHAPTER 8 • ARTICULATING EXPECTATIONS ABOUT SUPERVISION}

\section{Expectations}

TABLE 8.3 Participants' responses to individual statements. Note: Significant differences are indicated in bold.

\begin{tabular}{|c|c|c|c|c|}
\hline \multirow[t]{2}{*}{ STATEMENT } & \multicolumn{2}{|c|}{ Mean Rank } & \multirow[b]{2}{*}{ Z } & \multirow[b]{2}{*}{$p$} \\
\hline & Supervisor & Candidate & & \\
\hline 1) Select a research topic & 411.05 & 543.46 & -7.562 & .000 \\
\hline 2) Select a methodology & 396.49 & 551.19 & -9.133 & .000 \\
\hline $\begin{array}{l}\text { 3) Develop the timetable of research and } \\
\text { appropriate study programme }\end{array}$ & 392.61 & 551.32 & -9.437 & .000 \\
\hline $\begin{array}{l}\text { 4) Ensuring the student is introduced to and } \\
\text { aware of appropriate university facilities and } \\
\text { services }\end{array}$ & 399.77 & 550 & -8.714 & .000 \\
\hline 5) Decide on the frequency of meetings & 423.43 & 534.45 & -7.565 & .000 \\
\hline $\begin{array}{l}\text { 6) Ensure that the work is progressing and the } \\
\text { student is working consistently and on task }\end{array}$ & 399.90 & 546.48 & -8.882 & .000 \\
\hline $\begin{array}{l}\text { 7) Provide/facilitate emotional support and } \\
\text { encouragement to the student }\end{array}$ & 402.96 & 544.45 & -8.144 & .000 \\
\hline $\begin{array}{l}\text { 8) Decide if all drafts of written work should be } \\
\text { seen by the supervisor }\end{array}$ & 423.70 & 528.80 & -6.104 & .000 \\
\hline 9) Write the thesis & 436.08 & 525.24 & -5.532 & .000 \\
\hline $\begin{array}{l}\text { 10) Make decisions regarding the standard of } \\
\text { the thesis }\end{array}$ & 411.85 & 538.02 & -7.453 & .000 \\
\hline $\begin{array}{l}\text { 11) A supervisors should only accept a student when } \\
\text { they have specific knowledge of the student's } \\
\text { chosen topic }\end{array}$ & 488.63 & 491.74 & -.185 & .853 \\
\hline $\begin{array}{l}\text { 12) A personal, warm, supportive relationship } \\
\text { between supervisor and student is important for } \\
\text { successful candidature }\end{array}$ & 506.91 & 479.56 & -1.619 & .105 \\
\hline
\end{tabular}

\section{Responsibility to select research topic}

Candidate and supervisor expectations differed significantly as to who should choose the research topic $(U=84105.500, z=-7.562, p<.01): 41.8 \%$ of candidates believed that it was mostly their responsibility to select the research topic, whereas $39.8 \%$ of supervisors believed it to be a joint and equal responsibility. This effect can be described as 'medium' ( $r=.24)$.

\section{Selecting the methodology}

Candidate expectations regarding methodology selection ( $M$ rank $=551.19, n=$ 588) were significantly higher than supervisors' (M rank $=396.49, n=390)(U=$ 78388, $z=-9.133, p<.01)$, 'medium' effect $(r=.29)$. While $43.2 \%$ of students agreed that it is a joint and equal responsibility to select the research methodology, $41.8 \%$ agreed that it is mostly the student's responsibility. In comparison, only $21.8 \%$ 
of supervisors believed it is mostly the student's responsibility. They were more likely to believe it is a joint and equal responsibility (57.2\%).

\section{Development of the programme and timetable of study}

Candidates' expectations regarding development of a study programme and timetable ( $M$ rank $=551.32, n=586$ ) were significantly higher than supervisors' $(M$ rank $=392.61, n=389),(U=76872, z=-9.437, p<.01)$, 'medium' effect $(r=.3)$. While $49.3 \%$ of students believed development of a study programme and timetable is mostly their responsibility, $58.6 \%$ of supervisors suggested it is a joint and equal responsibility.

\section{Access to services}

The expectations of candidates regarding who should ensure the student has located and accessed all relevant services and facilities ( $M$ rank $=550, n=588$ ) were significantly higher than supervisors' (M rank $=399.77, n=391),(U=79674.50$, $z=-8.714, p<.01)$, 'medium' effect $(r=.28)$. While the majority of supervisors $(57.3 \%)$ believed it is mainly the supervisor's responsibility to ensure access to relevant services, students were more divided on the issue. Of the students, $40.6 \%$ agreed that it is mainly the supervisor's responsibility, yet $29.1 \%$ suggested it is a joint responsibility and $16.5 \%$ suggested it is mostly the student's responsibility.

\section{Regularity of meetings}

Candidates' expectations regarding who should decide on the frequency of meetings ( $M$ rank $=534.45, n=587$ ) were significantly higher than supervisors' ( $M$ rank $=$ 423.43, $n=392)$, $(U=88957.50, z=-7.565, p<.01)$, 'medium' effect $(r=.24)$. There was a greater belief among supervisors (26\%), relative to students (12.3\%), that deciding the frequency of meetings is mainly their responsibility.

\section{Consistency of work}

The expectations of candidates regarding who should ensure work is progressing at an appropriate rate ( $M$ rank $=546.48, n=586$ ) were significantly higher than supervisors' (M rank = 399.90, $n=389),(U=79705.50, z=-8.882, p<.01)$, 'medium' effect $(r=.28)$. There was a greater belief among supervisors (30.6\%) relative to students (14.8\%) that ensuring the work is progressing appropriately is mainly the supervisors' responsibility.

\section{Provision of emotional support and encouragement}

Expectations of candidates regarding who should provide emotional support and encouragement to the student ( $M$ rank $=544.45, n=586$ ) were significantly higher 
than supervisors' (M rank $=402.96, \mathrm{n}=389),(U=80898, z=-8.144, p<.01)$, 'medium' effect $(r=.26)$. Students either believed it was mainly the supervisors' responsibility (34.5\%) or a joint and equal responsibility (37.4\%), whereas, almost half $(48.6 \%)$ of supervisors believed it is mainly their responsibility.

\section{Revision of drafts}

Candidate expectations regarding the review of drafts ( $M$ rank $=528.80, n=586$ ) were significantly higher than supervisors' (M rank $=423.70, n=387),(U=88895$, $z=-6.104, p<.01)$, 'small' effect $(r=.20)$. There was a greater belief among students $(20.5 \%)$, relative to supervisors $(11.6 \%)$ that deciding if all drafts should be reviewed by the supervisor is mostly the student's responsibility.

\section{Assistance with writing the thesis}

Expectations of candidates regarding who should write the thesis ( $M$ rank $=525.24$, $n=586$ ) were significantly higher than supervisors' (M rank $=436.08, n=392$ ), $(U=$ 93913.50, $z=-5.532, p<.01)$, 'small' effect $(r=.18)$. While 63\% of students believed writing the thesis is their responsibility alone, $53.3 \%$ of supervisors reported this to be 'mostly' the student's responsibility, with $43.4 \%$ suggesting it is the student's responsibility alone.

\section{Responsibility for the standard of the thesis}

Candidates' expectations regarding who should decide on the standard of the thesis $(M$ rank $=538.02, n=584)$ were significantly higher than supervisors' ( $M$ rank $=$ $411.85, n=390),(U=84376, z=-7.453, p<.01)$, 'medium' effect $(r=.24)$. While $55.4 \%$ of supervisors believed decisions regarding the standard of the thesis is mainly their responsibility, $45.4 \%$ of students believed it to be a joint and equal responsibility.

\section{Knowledge of the chosen topic}

Candidates (72.9\%) and supervisors (76.7\%) agreed or strongly agreed that supervisors should only accept a candidate when they have specific knowledge of the student's chosen topic. No significant difference was found between the cohorts.

\section{Warm and supportive relationship}

When asked to comment on whether a warm, supportive relationship between the supervisor and candidate was important for successful programme completion, no significant difference was noted between the two groups. Candidates (85\%) and supervisors (87\%) both agreed or strongly agreed that this is an important part of the doctoral educative journey. 


\section{DISCUSSION}

The present study examined supervisor and student expectations with regard to RHD supervision, extending on previous research by Moxham et al (2013:345-354). The sample was international and included a range of disciplines. Findings underscored the notion that many expectations differ significantly between supervisors and students.

\section{Selecting topic and methodology}

Supervisors and students differed significantly in their expectations of who should select the research topic and methodology. While a large portion of students believed it is primarily the student's responsibility to select these aspects of the research, a large portion of supervisors believed it should be a joint and equal responsibility. This complements the findings by Moxham et al (2013:345-354). Wisker (2012: 1-20) contends that though the role and practice of supervision does differ across disciplinary contexts, it is apparent that across fields the introductory stage of a postgraduate project is of vast importance. There is a need to develop a topic and methodology that is original and contributes toward an identified need, whilst recognising boundaries and the need for flexibility. Students may wish to choose their own topic and methodology as they feel it will increase their engagement with the project. The RHD journey consists of knowledge co-construction, a process necessitating collegiality.

\section{Developing a study programme and timetable}

Expectations differed regarding the development of a study programme and timetable, including who should decide upon the regularity of meetings. About half of the students surveyed believed development of a study programme and timetable should primarily be their responsibility, while over half of the supervisors suggested it is a joint and equal responsibility. This aligns with past research by McGinty, Koo and Saeidi (2010:517-531) that surveyed RHD students from Australia, Malaysia and Iran regarding their perceptions of the supervisory relationship. Overall, students reported that they should take the lead role in the production of the thesis, with the supervisor taking the role of 'sounding board.' About two-thirds of the sample suggested they should be allowed to devise their own schedule, without having to constantly check with the supervisor.

Further, the current study found that supervisors were more likely than students to report that meeting frequency should mainly be decided by the supervisor, not the student. Again, this aligns with the findings of the study by McGinty et al (2010:517. 
531), in which over half the sample of students reported that they wanted to choose when to see their supervisor. However, approximately half of their sample suggested that they wanted supervisors to initiate meetings when required. These findings, and their relation to past research, highlight the complexity of the supervisor-student relationship. Past research has identified the importance of shared goals among students and supervisors (Anderson, Day \& McLaughlin 2006:149-168; Halse \& Malfroy 2010:79-92; Phillips \& Pugh 2005:86). Identifying expectations from the outset can assist in negotiating key aspects of the RHD, like programme and timetable development, and meeting regularity. Mutual agreement regarding meetings and timetables will ensure steady progress and open communication.

\section{Progress, assistance and consistency of work}

Supervisors contended, more strongly than students, that ensuring the project is progressing at an appropriate rate and consistency is mainly the supervisor's responsibility. Those who have supervised many candidates previously should have some notion of what is 'appropriate' with regard to progress. Similarly, a large portion of supervisors, compared to candidates, suggested it is their responsibility to ensure students are aware of and have access to relevant services and facilities on campus. Supervisors also believed, more than students, that it is primarily their responsibility to decide upon the standard of the thesis. It is in the supervisors' best interest to ensure the students complete their candidature at an appropriate rate, to a high standard, with access to appropriate services and facilities. Supervisors have the experience to understand the requirements of such a substantial piece of research (Moxham et al 2013:345-354). Bruce and Stoodley (2008:1-31), who worked with various supervisors across a range of disciplines to determine their awareness of supervision as teaching, found that supervisors perceive their role as one in which they can impart academic expertise, uphold academic standards, and contribute to society. Further, supervisors reported wanting to meet the students' learning needs and build on existing student abilities.

\section{Knowledge and a warm, supportive relationship}

There were two areas within which supervisor and student expectations aligned. The majority of participants agreed that supervisors should only accept candidates when they have specific knowledge of the area of research. An even larger proportion of each group agreed that a warm, supportive relationship between supervisor and student is important. McGinty et al (2010:517-531) also found that the majority of students suggested there be a close, personal relationship though they agreed this 


\section{PART THREE - CHANGING EXPECTATIONS OF POSTGRADUATE STUDENTS AND SUPERVISORS}

should be of a professional nature. Emotional support has arisen as an important aspect of successful candidature (Anderson et al 2006:149-168; Manathunga 2007:207-221). Given that damaging power imbalances can occur in supervisory relationships (Mantai \& Dowling 2015:106-121), emotional support cannot be overlooked as an essential aspect of the RHD journey.

\section{Practical implications}

Findings from the present study highlight that discussing expectations from the outset is essential. While every relationship differs, clarifying expectations from the outset can lessen communication difficulties and other issues down the line. Supervisors and students agree that the relationship should be warm and supportive. As such, the development of collegiality is important within the doctoral programme. An appreciation and understanding of relevant expertise and experiences that each person brings to the relationship is required.

\section{LIMITATIONS}

While the present study invited participants from a range of countries, the majority were from Australia. Future research may target a larger number of participants from other countries and regions in order to provide a more diverse and representative sample. Further, the addition of qualitative research methods may elucidate the reasoning behind various responses.

\section{CONCLUSION}

This international study highlights the importance of having early discussions regarding supervisory expectations. It contributes to the literature about the importance of the RHD supervisor-student relationship, and supports and extends upon the research by Moxham et al (2013:345-354). While supervisors and students agree that the relationship should be warm and supportive, expectations differ in other respects. Articulating expectations as early as possible opens the lines of communication and ensures a more enjoyable and worthwhile experience for those involved. This study's international sample highlights that these are not geographically isolated opinions or tied to area of research. An RHD is a shared journey between supervisor and student from which they can both learn and benefit. Articulating expectations from the beginning may well smooth the bumps in the road. 


\section{REFERENCES}

Anderson C, Day K \& McLaughlin P. 2006. Mastering the dissertation: Lecturers' representations of the purposes and processes of master's level dissertation supervision. Studies in Higher Education, 31 (2): 149-168.

Benmore A. 2014. Boundary management in doctoral supervision: How supervisors negotiate roles and role transitions throughout the supervisory journey. Studies in Higher Education, DOI: 10.1080/03075079.2014.967203

Bruce C \& Stoodley I. 2008. Student resources for the use of supervisors: ALTC Fellowship: Australian Government Department of Education, Employment and Workplace Relations. [Retrieved 30 October 2015] http://eprints.qut.edu.au/28585/1/Student_resources.pdf

Connell R \& Manathunga C. 2012. On doctoral education: How to supervise a PhD, 1985 2011 . Australian Universities Review, 54(1):5.

Dobson IR. 2012. PhDs in Australia, from the beginning. Australian Universities Review, 54(1):94.

Gardener SK. 2009. The development of doctoral students: Phases of challenges and support. ASHE Higher Education Report, 34(6):77-89.

Halse C \& Malfroy J. 2010. Retheorising doctoral supervision as professional work. Studies in Higher Education, 35(1):79-92.

Kandlbinder P \& Peseta T. 2001. In supervisors' words: An insider's view of postgraduate supervision. Sydney: Institute for Teaching and Learning, University of Sydney.

Lahenius K \& Ikävalko H. 2014. Joint supervision practices in doctoral education: A student experience. Journal of Further and Higher Education, 38(3):427-446.

Lange K \& Baillie C. 2008. Exploring graduate student learning in applied science and student-supervisor relationships: Views of supervisors and their students. Engineering Education, 3(1):30-34.

Litalien D \& Guay F. 2015. Droput intentions in PhD studies: A comprehensive model based on interpersonal relationships and motivational resources. Contemporary Educational Psychology, 41:218-231.

Manathunga C. 2007. Supervision as mentoring: The role of power and boundary crossing. Studies in Continuing Education, 29(2):207-221.

Mantai L \& Dowling R. 2015. Supporting the PhD journey: Insights from acknowledgements. International Journal for Research Development, 6(2):106-121.

McCallin A \& Nayar S. 2011 . Postgraduate research supervision: A critical review of current practice. Teaching in Higher Education, 1:1-12.

McGinty SC, Koo YL \& Saeidi M. 2010. A cross-country study on research students' perceptions of the role of supervision and cultural knowledge in thesis development. International Journal of Inclusive Education, 14(5):517-531.

Minichiello V \& Kottler JA (eds). 2010. Qualitative journeys: Student and mentor experiences with research. Thousand Oaks, CA: SAGE.

Mittwede PN, Noch EK \& Guo MH. 2014. A closer look at attrition in MD-PhD programs. Academic Medicine, 89(7):958-959. 


\section{PART THREE • CHANGING EXPECTATIONS OF POSTGRADUATE STUDENTS AND SUPERVISORS}

Moxham L, Dwyer T \& Reid-Searl K. 2013. Articulating expectations for PhD candidature upon commencement: Ensuring supervisor/student 'best fit.' Journal of Higher Education Policy and Management, 35(4):345-354.

Phillips EM \& Pugh DS. 2005. How to get a PhD? A handbook for students and their supervisors. Maidenhead, UK: Open University Press.

Picard M, Wilkinson, K \& Wirthensohn M. 2010. Perceptions and expectations of authorship: Towards development of an e-learning tool facilitating discussion and reflection between post-graduate supervisors and candidates. The Journal of the Education Research Group of Adelaide, 1(3):21-33.

Pyhältö K, Vekkaila J \& Keskinen J. 2015. Fit matters in the supervisory relationship: Doctoral students and supervisors' perceptions about the supervisory activities. Innovations in Education and Teaching International, 52(1):4-16.

Taylor S \& Kiley M. 2015. Supervising research degrees. In: H Fry, S Ketteridge \& S Marshall (eds.) A handbook for teaching and learning in higher education: Enhancing academic practice. 4th Edition. New York, Routledge. 180-192.

Wilks S. 2006. The process of supervisor selection. In: C Denholm \& T Evans (eds.) Doctorates downunder: Keys to successful doctoral study in Australia and New Zealand. Victoria: ACER Press. 15-22.

Wisker G. 2012. The good supervisor: Supervising postgraduate and undergraduate research for doctoral theses and dissertations. 2nd Edition. Basingstoke, UK: Palgrave Macmillan.

Yarwood-Ross L \& Haigh C. 2014. As others see us: What PhD students say about supervisors. Nurse Researcher, 22(1):38-43. 